\title{
A inserção feminina na política: uma análise da primeira edição do "Boletim da Federação Brasileira pelo Progresso Feminino"
}

Aline Isabel Waszak ${ }^{1}$

Resumo: Este artigo visa discutir a inclusão da mulher na política no contexto do Brasil republicano. Para isso, utilizarei o Boletim da Federação Brasileira pelo Progresso Feminino ${ }^{2}$, analisando o ponto de vista defendido por este grupo político, a classe a qual pertenciam, bem como os seus meios de inserção na política brasileira. A fonte data do ano de 1934 e foi o meio de divulgação dos ideais defendidos pela Federação Brasileira pelo Progresso Feminino. Criado no ano de 1922, uma de suas principais lutas foi o direito do voto e da emancipação feminina, teve como líder a sufragista Bertha Lutz.

Palavras-chave: Federação Brasileira pelo Progresso Feminino, Brasil República, Sufrágio Feminino, Feminismo, Bertha Lutz.

Abstract: This article aims to explore the inclusion of women in politics in the context of Brazilian Republican. For this, I will use the Bulletin of the Brazilian Federation for the Advancement of Women, analyzing the view expressed by this political group, the class which they belonged, as well as their means of insertion in Brazilian politics. The historical source is from 1934 and it was the vehicle of

\footnotetext{
${ }^{1}$ Graduanda em andamento em História da Universidade Federal do Paraná.

2 Fonte encontrada no site Museu Virtual Bertha Lutz. Disponível em: http://lhs.unb.br/bertha/ Acesso em: Maio de 2013.
} 
dissemination of the ideals espoused by the Brazilian Federation for the Advancement of Women. Founded in 1922, one of it's main struggles was the women's suffrage and women's emancipation, their leader was the suffragist Bertha Lutz.

Keywords: Brazilian Federation for the Advancement of Women, Brazilian Republican, Women's Suffrage, Feminism, Bertha Lutz.

Este trabalho tem o objetivo de analisar o primeiro exemplar do Boletim da Federação Brasileira pelo Progresso Feminino ${ }^{3}$, publicado no Rio de Janeiro e datado do mês de outubro de 1934. A fonte nos permite observar as ações deste grupo social, os ideais que defendiam bem como os meios que buscaram para inserir-se na política brasileira. A Federação Brasileira pelo Progresso Feminino esteve em atividade desde o ano de 1922, e já havia conquistado o voto feminino em 1932, dois anos antes da publicação de seu primeiro Boletim.

Uma das principais reivindicações do movimento foi, justamente, o sufrágio universal feminino, notamos através da leitura do Boletim que, mesmo com a realização do voto da mulher, as integrantes da Federação pelo Progresso Feminino ${ }^{4}$ continuaram a lutar por maiores benefícios para a mulher brasileira. A fonte em análise nos dá a oportunidade de observar algumas das conquistas já efetivadas pela

\footnotetext{
${ }^{3}$ O Boletim analisado foi retirado deste endereço: http://lhs.unb.br/bertha Acessado em: julho de 2013.

4 Doravante me reportarei a Federação Brasileira pelo Progresso Feminino como Federação ou FBPF.
} 
Federação e como tais conquistas são encaradas pelo grupo, bem como observar o desenvolvimento da imprensa feminina. Seguiremos para a análise efetiva da fonte, onde podemos observar tais processos com um maior detalhamento, problematizando como as crescentes modificações do status da mulher, no início do século XX, aparecem na fonte estudada e o modo que tal grupo buscava se inserir na política brasileira.

\section{O primeiro Boletim da Federação Brasileira pelo Progresso Feminino}

A publicação dos Boletins da FBPF ocorria mensalmente e teve seu primeiro exemplar em circulação no ano de 1934, no mês do Outubro. O Boletim era escrito para que as atividades da Federação fossem repassadas à população, sendo uma forma de propaganda para a causa do movimento social, ou seja, além da função informativa, o Boletim era também um meio utilizado para a propagação dos ideais feministas defendidos pelo grupo. Era publicado pelo Orgão Official[sic] da Opinião Feminina Organizada e continha textos escritos por várias participantes da Federação.

A primeira edição é composta por oito páginas, logo na primeira página, encontramos a manchete "Ás Urnas Cidadãs", direcionada ao público feminino. O Boletim possui linguagem rápida e acessível, apesar de conter uma coluna na língua inglesa, que 
provavelmente não poderia ser lida por qualquer pessoa, visto que parte da população sequer tinha acesso à alfabetização na língua portuguesa. Esta primeira parte do boletim se trata, à primeira instância, de uma comemoração em relação à conquista do voto feminino e sua importância, já que "a mulher representa metade da população, tanto quanto o homem faz jus á representação de que a Constituição lhe

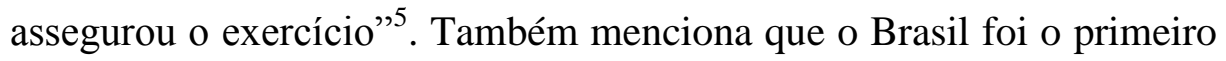
país a outorgar o direito de voto à mulher no continente sul-americano. Além de informar ás mulheres a importância de sua participação nas eleições que ocorreriam em Outubro, há também a propaganda de duas representantes femininas que se candidataram a cargos políticos: em primeiro plano aparece a Dra. Bertha Lutz, considerada líder da campanha feminista e candidata à deputação federal e em segundo, Stella Guerra Durval, candidata à Intendente Municipal.

A segunda página possui uma coluna intitulada "Nosso Boletim", escrita por Maria Eugenia Celso que explicita o objetivo da publicação de tal veículo, nas palavras dela o Boletim "tem como fim reunir e conçagrar[sic] em torno da ideia feminista todos os esforços dispersos, constituindo dest'arte(sic) uma espécie de centro irradiador"6. Maria Eugenia Celso também menciona que as publicações são feitas com o apoio das filiais de cada Estado e que o conteúdo escrito é

\footnotetext{
${ }^{5}$ Museu Bertha Lutz. Boletim da Federação pelo Progresso Feminino: Outubro de 1934. Publicado no sítio em 7 de fevereiro de 2013. Disponível em: http://hs.unb.br/bertha/?p=719 Aceso em: julho de 2013, p.1.

${ }^{6}$ Idem, p.2.
} 
substanciado pelo chamado "Decálogo Feminista" que se tratam de dez normas que devem ser seguidas a fim de obter a união das mulheres em favor da causa feminista.

As páginas seguintes da publicação referem-se à $2^{\mathrm{a}}$ Convenção Nacional Feminista que ocorreu na Bahia em 1931. Existe uma página que descreve todas as representantes de cada filial da Federação; estiveram presentes na Convenção membros das regiões da Bahia, Alagoas, Amazonas, Pará, Ceará, Pernambuco, Espírito Santo, Minas Gerais, Mato Grosso, Goiás, e do Rio Grande do Sul. A Convenção teve como membros de honra o Presidente Getúlio Vargas, o Ministro das Relações Exteriores, o Interventor Federal, entre vários outros membros da política brasileira. Era formado por várias Comissões Executivas, dentre elas a Comissão de Previdência Social e a Comissão Educação Cívica e Ação Política. O Boletim apresenta as conclusões e resoluções que foram votadas durante a $2^{\mathrm{a}}$ Convenção, mostrando uma listagem que mostra todas as propostas de alteração de leis que foram sugeridas durante a realização do evento.

$\mathrm{Na}$ parte final da publicação, encontramos um artigo que faz um relato das resoluções ocorridas na Convenção Brasileira e parabeniza as conquistas das feministas brasileiras; esta coluna é apresentada escrita na língua inglesa, isto nos dá a entender que a Federação tinha um reconhecimento internacional de seus feitos. A última coluna presente nesta primeira edição do Boletim FPPF é um 
relato das medidas que entraram na Constituinte brasileira devido aos esforços de Bertha Lutz.

\section{Um breve histórico da Federação Brasileira pelo Progresso} Feminino

Antes de se tornar efetivamente a Federação Brasileira pelo Progresso Feminino, existiu a Liga para Emancipação Feminina, que foi fundada por Bertha Lutz em 1919; após regressar de seus estudos foras do país e ter mantido relações com sufragistas na Europa e nos Estados Unidos. Lutz volta ao Brasil com o objetivo de conscientizar as mulheres brasileiras sobre a importância da sua participação na política. $^{7}$ Segundo Bonato $^{8}$, posteriormente, devido à grande adesão feminina de outros Estados brasileiros e depois da participação de Bertha Lutz na Conferência Pan-Americana de mulheres, ocorrida nos Estados Unidos, a Federação para o Progresso Feminino foi criada em 19 de agosto de 1922, tendo a sede principal no Rio de Janeiro.

O grupo não tinha relações com nenhum partido político ou era ligado a algum outro movimento social. Podemos afirmar que, de forma

\footnotetext{
${ }^{7}$ MOURELLE, Rodrigo et al. A Federação Brasileira pelo Progresso Feminino e o governo de Getúlio Vargas na década de 1930: estratégias e paradoxos do movimento feminista no Brasil. Colóquio Internacional Gênero, Feminismos e Ditaduras no Cone Sul. UFSC, 4 a 7 de maio de 2009, p.2. Disponível em: http://www.coloquioconesul.ufsc.br/rodrigo_cavaliere.pdf Acesso em: julho de 2013. 8 BONATO, Naílda Marinho da Costa. O Fundo Federação Brasileira pelo Progresso Feminino: uma fonte múltipla para a história da educação das mulheres. In: Acervo, Rio de Janeiro, v.18, nº 1-2, jan./dez. 2005, p.135.
} 
predominante, as mulheres que fizeram parte da Federação eram pertencentes à classe burguesa e foram elas que encabeçaram o movimento em seus primeiros anos. Segundo os estudos de June Hahner: "das 170 mulheres que se juntaram à FBPF em 1922, o ano de sua fundação, 121, ou 71\%, declararam uma profissão" ${ }^{9}$. Exerceram funções na Federação mulheres profissionais nas áreas de advocacia, farmácia, professoras e funcionárias públicas, mas a maioria era de encadernadoras.

Associada à Aliança Internacional pelo Voto Feminino, a Federação mantinha relações com outras sufragistas, em especial as do continente americano, tendo destaque à participação de Carrie Chapman Catt, que foi líder do movimento norte-americano. ${ }^{10}$ A Federação, encabeçada por sua presidente Bertha Lutz, tinha como uma de suas metas "promover a educação e profissionalização das mulheres"11, pois Bertha Lutz entendia que a compreensão da população feminina quanto ao valor de sua participação na política só seria efetiva se as mulheres recebessem a educação adequada. Uma das primeiras conquistas da Federação, logo no ano de 1922, foi a permissão para que moças pudessem estudar no Colégio D. Pedro II no Rio de Janeiro ${ }^{12}$.

\footnotetext{
${ }^{9}$ HAHNER, June E. A Mulher brasileira e suas lutas sociais e políticas: 18501937. São Paulo: Brasiliense, 1981, p.110.

${ }^{10}$ Idem, p.106.

${ }^{11}$ SOUSA, Lia G.; SOMBRIO, Mariana; LOPES, Maria. Para ler Bertha Lutz. In: Cadernos Pagu . Campinas: UNICAMP, janeiro-junho de 2005, p. 315.

${ }^{12}$ HAHNER, June. Op cit, p.122.
} 
A principal campanha e o maior esforço de luta da FBPM foi a sua persistência em relação à questão do voto feminino. Durante toda a década de 20, a Federação e suas líderes sufragistas lutaram a fim de conquistar o voto, para isto buscaram aproximação com líderes políticos e utilizaram-se da publicidade, como podemos notar pela fonte analisada. Com o argumento de que o Brasil "deveria seguir a liderança de outras "nações civilizadas" que tivessem oferecido às mulheres "igualdade de direitos"”,13 as sufragistas buscavam aproximação com a Assembleia e participavam de reuniões do Congresso. Em 1927 foi apresentado um projeto de lei, acompanhado por uma petição com a assinatura de duas mil mulheres, que exigia a aprovação da lei que estendia o voto às mulheres. Sem obter sucesso nesta tentativa, a causa defendida pela Federação ganhou força e a campanha publicitária foi intensificada. Apesar da insistência do grupo em mudar a legislação, as líderes do movimento sufragista no Brasil "não expressaram desejo significativo por uma reestruturação radical do sistema político da nação, muito menos de sua sociedade" ${ }^{14}$.

Foi só após a mudança na legislação do Rio Grande do Norte, feita pelo político defensor do sufrágio feminino, Juvenal Lamartine Faria, que concedeu o voto às mulheres, o movimento aumentou ainda mais a sua força. Depois de muito esforço, no final de Agosto de 1931, o governo realizou um código eleitoral provisório que dava o direito de

\footnotetext{
${ }^{13}$ Idem, p. 113.

${ }^{14}$ Idem, p. 114.
} 
voto ao público feminino. Inicialmente, o projeto foi criticado, já que dava direito de voto às mulheres somente com a permissão de seu marido e para determinados grupos de mulheres. Após o contato direto do grupo sufragista com o Presidente da República, Getúlio Vargas, o voto feminino se tornou, finalmente, realidade através do novo código decretado em 24 de fevereiro de 1932 que "dava o direito de voto às mulheres sob as mesmas condições que aos homens" ${ }^{\prime 15}$.

\section{O contexto Histórico do período de publicação do Boletim da FBPF}

O período que abrange os fins do século XIX até meados do século XX, trata-se de um contexto onde ocorreram profundas mudanças que desestabilizaram a sociedade e a cultura tradicional. Para Sevcenko, no início do período republicano, indivíduos passam a lutar por meios de inserção social, buscando "sentidos de pertencimento à coletividade e de autonomia individual" ${ }^{\text {"16 }}$. No início do século XX, em especial na Era Vargas, temos o advento do movimento modernista no Brasil, que passa a "denunciar com maior ênfase os conhecimentos considerados atrasados"17. Podemos inserir aqui, a luta da Federação, já

${ }_{15}^{15}$ Idem, p. 120.

${ }^{16}$ SEVCENKO, Nicolau. "Introdução: O Prelúdio Republicano, astúcias da Ordem e Ilusões do Progresso". In: NOVAIS, Fernando A. (Coord. Geral). História da vida privada no Brasil. São Paulo: Companhia das Letras, 1998, Vol.3, p.10.

${ }^{17}$ OLIVEIRA, Lúcia Lippi. Sinais de modernidade na era Vargas: vida literária, cinema e rádio. IN: FERREIRA, Jorge; Lucília de A. N. DELGADO (Orgs.). O Brasil 
que o movimento sufragista foi, inicialmente, uma bandeira levantada pela classe burguesa que tinha em mente que tal processo demonstrava sinais de modernidade e progresso para o país ${ }^{18}$.

Bonato e Costa Coelho definem o período como um "caldo ideológico" 19 , formado por diversos pensamentos e movimentos que ora se chocam ora se atraem. Juntamente com a ideia de progresso, nota-se a importância da educação para construir novos princípios na sociedade brasileira, "buscando a manutenção da ordem vigente"20. Tal preocupação com a educação brasileira pode também ser notada pelo movimento feminista da época, como já elucidamos acima.

Durante os séculos XVIII e XIX ocorria a definição dos espaços de acordo com o gênero: a esfera pública deveria ser destinada aos homens, enquanto a esfera doméstica era destinada ao ambiente privado e doméstico, devido as suas "habilidades naturais" direcionadas à maternidade. Com o processo de modernização e urbanização no século $\mathrm{XX}$, este quadro passa a sofrer mudanças que afetam a vida

republicano. O tempo do nacional-estatismo: do início da década de 1930 ao apogeu do Estado Novo. Rio de Janeiro: Civilização Brasileira, 2003, p.324.

${ }^{18}$ GOLDENBERG, Mirian; TOSCANO, Moema. A Revolução das Mulheres: um balanço do Feminismo no Brasil. Rio de Janeiro: Renavan, 1992, p.25.

${ }^{19}$ BONATO, Naílda Marinho da Costa; COELHO, Lígia Martha Coimbra da Costa. Concepções de educação Integral na década de 30: as Teses do II Congresso Internacional Feminista. Goias: IV Congresso Brasileiro de História da Educação, 2006 p.1. Disponível em:_http://www.sbhe.org.br/novo/congressos/cbhe4/individuaiscoautorais/eixo01/Nailda\%20Marinho\%20da\%20Costa\%20Bonato\%20e\%20Ligia\%2 0Martha\%20Coimbra\%20da\%20Cos.pdf Aceso em: julho de 2013.

${ }^{20}$ Ibidem. 
social das mulheres ${ }^{21}$. De modo vagaroso há a inserção delas no mundo trabalhista, principalmente das mulheres de classes baixas. Gradativamente, o público feminino da classe média também passa a realizar trabalhos que eram socialmente aceito para as mulheres. Larissa Seixas chama atenção para o fato de que mesmo antes do feminismo como um movimento de massa dos anos 60 , as mulheres já atuavam no campo público, buscando diversas formas de expressão ${ }^{22}$.

O governo varguista iniciado nos anos 30 foi marcado uma presença mais forte do Estado nas relações sociais, considerando as reformas de cunho populista realizadas pelo presidente; muitas destas medidas acabavam por reforçar a separação dos papéis de gênero. Há a valorização da mulher no mercado de trabalho, mas também do seu desempenho em realizar tarefas domésticas e a manutenção da família. Observamos então, uma posição contraditória sobre o papel da mulher, já que a "a formação educacional mais aprofundada suscitava a ambição de exercer funções fora do lar, mas por outro lado os valores maternais e de domesticidade permaneciam na base da concepção de feminilidade na época" 23.

${ }^{21}$ SEIXAS, Larissa Selhorst. O Feminismo no bom Sentido: o Centro Paranaense Feminino de Cultura e o lugar das mulheres no mundo público (Curitiba-1933-1958). 2011. 141 f. Tese (Doutorado em História)-Setor de Ciências Humanas, Letras e Artes. Universidade Federal do Paraná, Curitiba, 2011, p. 28.

${ }^{22}$ Idem, p. 30.

${ }^{23}$ Idem, p. 56. 


\title{
A mudança no status da mulher e os meios de inserção política através do Boletim
}

Segundo June Hahner, um dos meios mais eficientes da publicidade dos ideais feministas foi a imprensa. Com a publicação da primeira edição, podemos dizer que a disseminação de seus ideais ocorreu de forma mais ampla. Esta primeira edição cumpre esta função e exprime um manual com dez passos a serem seguidos pela mulher:

\author{
Decalogo Feminista \\ Toda mulher deve: \\ $1^{\circ}$ Exercer seus direitos políticos e cumprir \\ seus deveres \\ civicos [sic] \\ $2^{\circ}$ Interessar-se pelas questões publicas do \\ paiz[sic] \\ $3^{\circ}$ Ter ocupação útil á sociedade \\ $4^{\circ}$ Alistar-se e votar \\ $5^{\text {a }}$ Votar consciente e criteriosamente \\ $6^{\circ}$ Não entregar seu titulo eleitoral \\ $7^{\circ}$ Dedicar-se à causa feminista, crente no \\ triumpho[sic] \\ dos seus ideaes[sic] \\ $8^{\circ}$ Votar somente em quem for feminista \\ $9^{\circ}$ Bater-se pela conquista e pleno \\ exercicio de seus direitos sociae[sic] e politicos \\ $10^{\circ}$ Trabalhar pelo aperfeiçoamento moral, \\ 24 \\ Intellectual [sic], social e civico da mulher
}

\footnotetext{
${ }^{24}$ Museu Bertha Lutz, Op. cit., p.2.
} 
O Decálogo Feminista resume os ideais defendidos, e explicitados anteriormente, pela Federação. Observamos o papel primordial do Boletim em reforçar a importância do papel da mulher na política e a manutenção dos valores feministas, já que, mesmo após a efetivação do voto, foi necessária uma constante conscientização das mulheres quanto a isto. Por mais que, de início, a porcentagem de mulheres que participaram da votação tenha sido pequena, observamos a entrada feminina no campo político e na vida pública em seu esforço de representar-se frente à sociedade; tais fatores alterariam a sociedade nas décadas seguintes.

Outra tática política que pode ser percebida através da leitura do Boletim será a notável presença masculina na $2^{\mathrm{a}}$ Convenção Nacional Feminista, expresso nas páginas do informativo. Nesta Convenção, que consagrou várias mudanças legislativas, sociais e trabalhistas, em direção das mulheres, observamos a participação de destaque de Getúlio Vargas, presidente da República no período. A fim de não procurar entrar em um conflito segregacionista, as mulheres da Federação buscavam não utilizar de contestações radicais contra os homens, pois os enxergavam como aliados para conquistar seus objetivos.

Sendo assim, uma de suas principais estratégias, além da publicação de boletins, propagandas em rádios e jornais e organização 
de eventos, era baseada numa rede de relacionamentos ${ }^{25}$, onde os membros da Federação buscavam aproximação com políticos e também com suas esposas. Cavaliere comenta que além da relação que as sufragistas mantiveram com Getúlio Vargas, também trocavam cartas com sua esposa, Darcy. Estas cartas continham elogios aos políticos a fim de estreitar laços para que a Federação alcançasse seus objetivos, já que tais mulheres, nas palavras de Sohiet, "buscam sua instrumentalização com vistas a ampliar seu espaço de atuação, o que acreditavam inviável de outra forma" ${ }^{26}$.

Pela leitura do Boletim, também encontramos a defesa, por parte das Comissões de Previdência Social e Educação Cívica e Ação Política, de um discurso favorável à educação feminina. Tais comissões queriam "promover a educação da mulher e elevar o nível da instrução feminina e assegurar á mulher os direitos políticos que a Constituição lhe confere e preparala[sic] para o exercício intelligente[sic] desses direitos"27. Também visavam "proteger as mães e a infância[sic] e obter garantias legislativas e praticas para o trabalho feminino"28. Através destes trechos, notamos, novamente, a mudança do papel social da mulher, que passa a requerer direitos em relação à sua educação, visto a sua recente entrada no mercado de trabalho. Por outro lado, ainda há

\footnotetext{
${ }^{25}$ MOURELLE, Rodrigo et al. Op. cit., p.3

${ }^{26}$ SOIHET, Rachel. A pedagogia da conquista do espaço público pelas mulheres a e militância feminista de Bertha Lutz. In: Revista Brasileira de Educação, nº 15 , Set/ Out/ Nov/ Dez de 2000, p.106.

${ }^{27}$ Museu Bertha Lutz, Op cit., p.3.

${ }^{28}$ Ibidem.
} 
mentalidade de que a mulher pertence ao lar e seu papel biológico é cuidar de seus filhos e da manutenção do lar. Para Sohiet, isso se trata de uma prática utilizada pelas mulheres; elas aceitavam as regras e os valores da sociedade burguesa tradicional a fim de se integrarem nela de forma plena ${ }^{29}$.

O Boletim ainda nos apresenta uma série de leis que foram alteradas após a $2^{\circ}$ Convenção Nacional Feminista, todas elas apresentam um avanço em relação à posição social anterior da mulher e demonstram uma preocupação com as mulheres das mais diversas classes sociais. Notamos isto quando defendem o direito do operariado feminino, que "idêntica[sic] por trabalho egual[sic], sem distincção do sexo do trabalhador e da interrupção do trabalho sem perda de venciomentos na occasião[sic] do parto" ${ }^{\text {30 }}$.

Um item de destaque no Boletim é o pedido de educação para a "formação da Mulher Cidadã, comprehendendo[sic] seus direitos e

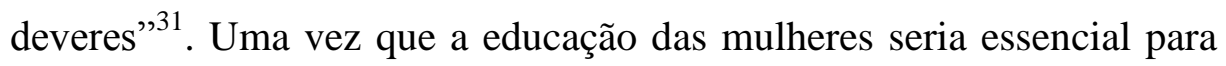
que mais brasileiras tivessem a conscientização da relevância do sufrágio feminino, membros da Federação utilizam-se do argumento progressista, onde a educação é um fator primordial para a existência de uma sociedade desenvolvida, para que o direito à educação seja também dado às mulheres.

\footnotetext{
${ }^{29}$ Idem, p. 105.

${ }^{30}$ Museu Bertha Lutz, Op. cit., p. 5.

${ }^{31}$ Idem, p.6.
} 
Cada item modificado na legislação merece atenção especial e diferenciada, porém, minha análise restringiu-se a observar a função do Boletim enquanto propagador dos ideais da Federação e enquanto expositor das ações políticas utilizados pelos membros da FBPF.

\section{Considerações Finais}

Com a leitura da fonte e a inserção em seu contexto histórico, foi possível compreender as ações políticas da Federação pelo Progresso Feminino, bem como observar seus inúmeros avanços dentro da sociedade em que estavam imersas. Apesar de haver a manutenção da mulher enquanto responsável pelas atividades domésticas, ressaltando o seu papel de reprodutora, as conquistas da Federação não podem ser deixadas de lado, considerando que suas ações foram de grande importância no que se refere à inserção da mulher na esfera pública.

Atentemos para o fato que Rachel Soihet chama atenção de que "as feministas focalizadas não teriam sido capazes de perceber a conexão existente entre a mística da "missão natural da mulher" e sua inferiorização" ${ }^{\text {32 }}$. Ou seja, por mais que as atividades da Federação não tenham provocado sérias mudanças no que tange a consciência de gênero, não podemos realizar operações anacrônicas a fim julgá-las por

32 SOIHET, Rachel. Op. cit., p.106. 
sua atuação, que também pode ser entendida como uma tática política, como argumenta Soihet.

Portanto, entendemos o papel da Federação enquanto potencializador das mudanças do status da mulher brasileira na primeira metade do século XX. Após terem sido oprimidas historicamente, as mulheres passam a ter espaço no âmbito público e tem o direito de se posicionar enquanto cidadãs através do esforço alcançado por um distinto grupo de brasileiras que, apesar das dificuldades encontradas, foi essencial para a mudança do papel da mulher no Brasil.

\section{Fonte}

Museu Bertha Lutz ${ }^{33}$. Boletim da Federação pelo Progresso Feminino: Outubro de 1934. Publicado no sítio em 7 de fevereiro de 2013. Disponível em: http://hs.unb.br/bertha/?p=719 Aceso em: julho de 2013

\section{Referências Bibliográficas}

BONATO, Nailda Marinho da Costa. O Fundo Federação Brasileira pelo Progresso Feminino: uma fonte múltipla para a história da educação das mulheres. In: Acervo, Rio de Janeiro, v.18, nº 1-2, jan./dez. 2005, pp.131-146.

${ }^{33} \mathrm{O}$ sítio esclarece que este conjunto de Boletins dispostos no site foram preservados na Biblioteca Riograndense, na cidade de Rio Grande, RS. Eles foram disponibilizados para o site Museu Bertha Lutz através da pesquisadora Mônica Karaw. 
BONATO, Naílda Marinho da Costa; COELHO, Lígia Martha Coimbra da Costa. Concepções de educação Integral na década de 30: as Teses do II Congresso Internacional Feminista. Goias: IV Congresso Brasileiro de História da Educação, 2006. Disponível em: http://www.sbhe.org.br/novo/congressos/cbhe4/individuaiscoautorais/eixo01/Nailda\%20Marinho\%20da\%20Costa\%20Bonato $\% 20$ e\%20Ligia\%20Martha\%20Coimbra\%20da\%20Cos.pdf Acesso em: julho de 2013.

HAHNER, June E. A Mulher brasileira e suas lutas sociais e políticas: 1850-1937. São Paulo: Brasiliense, 1981.

\section{MOURELLE, Rodrigo et al. A Federação Brasileira pelo Progresso}

Feminino e o governo de Getúlio Vargas na década de 1930: estratégias e paradoxos do movimento feminista no Brasil. Colóquio Internacional Gênero, Feminismos e Ditaduras no Cone Sul. UFSC, 4 a 7 de maio de 2009. Disponível em: http://www.coloquioconesul.ufsc.br/rodrigo_cavaliere.pdf Acesso em: julho de 2013.

OLIVEIRA, Lúcia Lippi. Sinais de modernidade na era Vargas: vida literária, cinema e rádio. IN: FERREIRA, Jorge ; Lucília de A. N.

DELGADO (Orgs.). O Brasil republicano. O tempo do nacionalestatismo: do início da década de 1930 ao apogeu do Estado Novo. Rio de Janeiro: Civilização Brasileira, 2003, pp.323-349.

SEIXAS, Larissa Selhorst. O Feminismo no bom Sentido: o Centro Paranaense Feminino de Cultura e o lugar das mulheres no mundo público (Curitiba-1933-1958). 2011. 141 f. Tese (Doutorado em História)-Setor de Ciências Humanas, Letras e Artes. Universidade Federal do Paraná, Curitiba, 2011. 
SEVCENKO, Nicolau. "Introdução: O Prelúdio Republicano, astúcias da Ordem e Ilusões do Progresso". In: NOVAIS, Fernando A. (Coord. Geral). História da vida privada no Brasil. São Paulo: Companhia das Letras, 1998, Vol.3, pp. 7-48.

SOIHET, Rachel. A pedagogia da conquista do espaço público pelas mulheres e a militância feminista de Bertha Lutz. In: Revista Brasileira de Educação, nº15, Set./Out./Nov./Dez. de 2000, pp.97-117.

SOUSA, Lia G.; SOMBRIO, Mariana; LOPES, Maria. Para ler Bertha Lutz. In: Cadernos Pagu. Campinas: UNICAMP, janeiro-junho de 2005.

TOSCANO, Moema. A revolução das mulheres: um balanço do feminismo no Brasil. Rio de Janeiro: Renavan, 1992. 